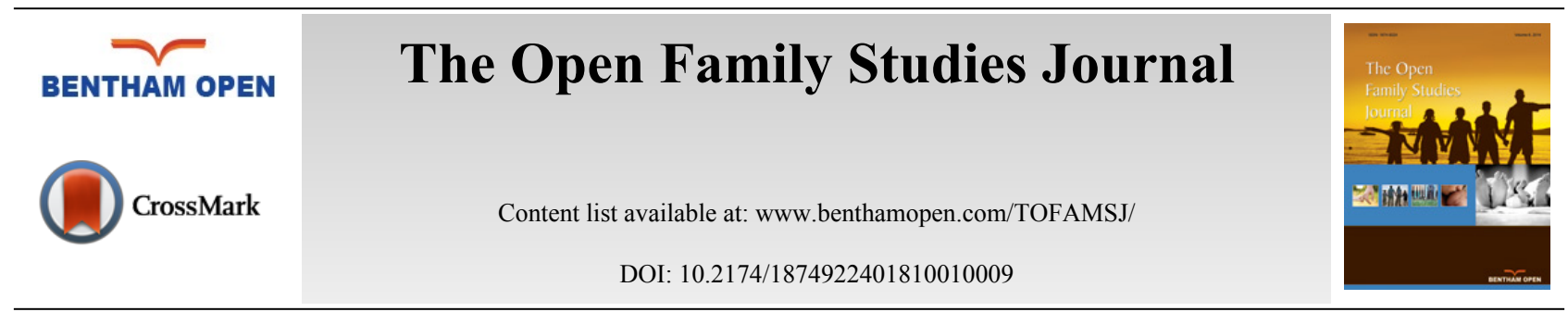

CLINICAL TRIAL STUDY

\title{
The Relationship between Peer Victimization, Perceived Parental Support, Family Characteristics and Internalizing Symptoms. A Cross-Sectional Study
}

\author{
Bachler Egon $^{1, *}$, Nickel Marius ${ }^{3,4}$ and Bachler Herbert ${ }^{2}$ \\ Salzburg, Austria \\ ${ }^{2}$ Medical University of Innsbruck, Innrain 52, 6020 Innsbruck, Austria \\ ${ }^{3}$ Medical University of Graz, Clinic for Psychiatry, Graz, Austria \\ ${ }^{4}$ Ameos Clinika SommersbergerseestraBe 395, 8990 Bad Aussee, Austria
}

${ }^{I}$ Institute of Synergetic and Psychotherapy Research, PMU Paracelsus Medical University, Ignaz Harrer Street 79,

Received: November 05, 2017

Revised: February 22, 2018

Accepted: March 07, 2018

\begin{abstract}
:
Background:

Bullying and peer victimization are important, yet underestimated public health issues.
\end{abstract}

\section{Methods:}

Data were obtained in a sample of $\mathrm{N}=3454$ children at the age of $12.6(+/-1.3)$ in Austria. $75 \%$ of the participants were not involved in bullying (uninvolved), $16 \%$ were victims, $4 \%$ bully/victims and $5 \%$ bullies. We applied a multivariate regression model relating to gender, established a classification into bullying and victimization, and investigated parental behavior, family characteristics, physical or mental illness of a parent, as well as internalizing symptoms of pupils.

Results:

Our data analysis demonstrated gender-related effects and the development of internalizing symptoms: Boys showed fewer internalizing symptoms than girls. Pupils with low perceived parental support displayed higher symptomatic scores. The variables of family break-up and parental health led to similar observations. Victims have an approximately $30 \%$ higher score on the internalizing scale than bullies and $60 \%$ higher scores than uninvolved. The results of the regression model indicated that these predictors explained $25 \%$ of the variance.

\section{Conclusion:}

School policies, teachers, parents, the media, school physicians, as well as GPs must recognize early warning signs of bullying and diligently assess risk behaviors. Early social support (by parents and teachers) is discussed as an important protective factor.

Keywords: Bullying, Peer victimization, Social support, Mental health, Child and adolescent health.

\section{INTRODUCTION AND BACKGROUND}

Bullying is an asymmetrical and interpersonal form of recurring or non-recurring aggressive behavior (physical, verbal, social and electronic). It takes place in preschool, during adolescence and penetrates adult working places. Given its proven prevalence, peer victimization is an underestimated, yet common and substantial stress and adversity factor in adolescents [1,2]. Consequently, bullying and peer victimization are important international public health

\footnotetext{
* Address correspondence to this author at the Institute of Synergetic and Psychotherapy Research, PMU Paracelsus Medical University, Ignaz Harrer
} Street 79, Salzburg, Austria; E-mail: dr.egon.bachler@t-online.de 
issues. Data from 11-, 13- and 15-year-old school-children in 40 countries (US, Canada, Europe N = 202.056) showed that $8.6 \%$ to $45.2 \%$ of boys and $4.8 \%$ to $35.8 \%$ of girls reported bullying at school [3]. Further empirical data documented the prevalence rates of school bullying in the United States with a frequency of at least once in the last two months; $20.8 \%$ reported physical bullying, 53.6\% verbal bullying, 51.4\% social bullying and $13.6 \%$ electronic bullying [4]. In Europe [5] the number of pupils (aged 13) who reported being bullied was highest in the following countries: Greece (22\%), Austria (19\%) and Portugal (16\%). Sweden (4\%), Spain (5\%) and Iceland (7\%) showed the lowest prevalence rates. Austrian boys at the age of 13 showed a percentage of 26\%, girls one of $11 \%$ (a total of $19 \%$ ). Girls in Hungary and Greece showed higher rates of peer victimization than boys. No country showed more female than male bullies. This cross-national OECD survey further demonstrated that peer victimization is more prevalent at the age of 15 than at the age of 13 when there are more migrants in class.

Peer victimization is thus an underestimated, yet common and substantial stress factor with respect to individual vulnerability, affecting from about $10 \%$ up to more than $50 \%$ of all children and adolescents [6] - the numbers varying according to which sets of diagnostic criteria are being used. Different researches suggest that victimization reaches its peak between the ages of 12 and $14[7,8]$.

The meta-analysis of [9] demonstrated that bullied children and adolescents have a statistically significantly higher risk of developing psychosomatic problems than non-bullied youths. The effect size decreased with an increase in proportion of girls in the studied samples [8] showed that peer victimization effected a higher risk of poor health and impacted on the development of prosperity and social skills in youth and adulthood. Furthermore, peer victimization in childhood was strongly associated with actual pain ratings [10]. Empirical evidence was given by a five-decade longitudinal study, which demonstrated that peer victimization leads to higher rates of depression in adulthood, as well as to higher rates of anxiety disorders and of suicidality [11]. Bullied pupils showed higher scores on all clinical scales of the Trauma Symptom Checklist for Children (TSCC) [12, 13] confirmed the association between being bullied and psychiatric outcomes, especially agoraphobia, generalized anxiety and panic disorders. Children and adolescents with a history of being bullied reported three times higher scores of suicidal ideation compared to those who were uninvolved $[14,15]$ showed that peer victimization was associated with higher scores for emotional and depression symptoms. In a meta-analysis of clinical samples [16] even detected a strong empirical relationship between an increased frequency/severity and longer duration of being bullied and the development of psychosis [17] showed a strong relationship between peer victimization and a lower health-related quality of life in adulthood. The relationship between early stress experiences and an increased vulnerability to psychological, psychosomatic, psychiatric and physical disorders has been confirmed in many different studies. We can assume that there is a bidirectional relationship (antecedents and consequences of peer victimization) between peer victimization and internalizing problems [18].

Bender et al [19] reported long-term effects of bullying, especially a propensity for delinquency. Their empirical research demonstrated that adolescent bullying is a predictive key risk factor for maladaptive and antisocial behavior in adulthood. But conversely, peer-victimization was not related to anti-social behavior outcomes.

In general, we can detect a strong empirical evidence for a causal relationship between individual genetic dispositions, epigenetic processes over the course of life, stress-related developments of the functionality of the hypothalamic pituitary adrenocortical system (HPA axis), and early distress in childhood. Chronic stress, caused, for example, by long-time peer victimization, influences the functionality of the HPA axis and thereby affects the individual risk of developing severe mental disorders. It also affects the development of cognitive abilities and thus influences a pupil's performance at school [20]. The HPA axis is the best-studied stress response system [21 - 23]. We can summarize that high adversity scores in early and late childhood have a high long-term impact on the causal pathways of adult mood disorders, anxiety disorders, substance abuse or dependence and posttraumatic stress disorders. These disorders also show frequent comorbidity [1]. The individual risk of developing mental health problems through peer victimization is caused and moderated by the personal characteristics of the child, family-related resources, perceived peer relationship (group position of the bullied children or adolescents), situational factors, as well as by the frequency, the duration and the type of peer victimization and the accumulation of various adversity factors. Parentchild interactions is the most important protective parameter, it is the key factor for HPA Axis functionality long term brain and mental health effects $[24,25]$.

The present study looked at a representative random sample and investigated the varying severity of symptom development in pupils at the age of 12 to 14 (uninvolved pupils, victims, bullies and bully/victims). Through different regression models we tested the associations between these four groups and various family-related variables: Our main interest (hypothesis) was to examine the associations between gender, perceived parental support, family break-up, 
parental health and the development of internalizing symptomatology (vegetative symptoms, stress-related cognitive problems, emotional instability, anxiety, somatization, depression, sleep disturbances). Finally, we want to derive from these empirical data further results in order to identify evidence-based guidelines for bullying (bullying recommendations) aimed at parents, teachers and physicians (GPs and pediatricians), which should allow an early detection and prevention of peer victimization.

\section{METHODS}

\subsection{Participants}

A random sample was collected in urban and rural public secondary schools in one Austrian state (Tyrol). The overall sample was $\mathrm{N}=3454$ children at the age of $12.6(+/-1.3) ; 51 \%$ of the participants were male and $49 \%$ were female. Respondents were excluded if the questionnaire was not fully (age of the father, age of the child, bully/victim, health of the child) or not plausibly $(\mathrm{n} 1=29.1 \%)$ completed, or if the child was older than 15 : $\mathrm{n} 2=789(23 \%)$. Our final dataset included $\mathrm{N}=2637$ pupils. Mean age was 12.59 (+/- 1.3) (= uninvolved, $\mathrm{N}=2002,51 \%$ female, $49 \%$ male); 12.51 $(+/-1.31)(=$ victim, $\mathrm{N}=412$, 49\% female, 51\% male); 12.8 (+/- 1.31) (= bully/victim, $\mathrm{N}=96,28 \%$ female, $72 \%$ male); 13.17 (+/- 1.36) (= bully, $\mathrm{N}=127,30 \%$ female, $70 \%$ male). The questionnaires were distributed to the entire class. We surveyed 30 schools in a population-based cross-sectional study. Socio-demographically, 4 school classes are set within a town of 10,000 to 15,000 inhabitants; 26 come from more rural regions with under 10,000 inhabitants. The district school boards designated three schools from each school district ( $=10$ districts in Tyrol). The respective principals were informed that the questionnaire should be filled out during summer term 2013. 10 schools did not want to participate. The main reasons for refusing to cooperate were stated as follows: "We already have so many projects" and "There is no bullying at our school". Teachers were instructed by an accompanying letter and a hotline was installed for further questions. There were 2 organizational questions. Data were collected through anonymous self-report questionnaires administered in the classroom. Following instructions, the pupils were asked to fill out the questionnaires simultaneously, either online on a PC $(\mathrm{N} 1=3031)$ or in a paper pencil version $(\mathrm{N} 2=423)$. The questionnaires were then collected.

\subsection{Measures and Procedure}

We used a self-completion questionnaire (TGAM - Tyrolean Society of General Medicine, consisting of 58 items) which included questions about bullying, victimization, personal and family resources, socio-demographic variables, health outcomes, as well as items on social support (parenting, siblings, relatives, classmates, friends, teachers, etc.). 15 items (TGAM 1-15), modeled upon the School-Mobbing Questionnaire (SMOB), assessed bullying and victimization [27]. The SMOB has five subscales ("attacks on your relationships," "you are rejected by others," "attacks on the image that you have in others," "others demand things of you that you feel are offensive" and "you are experiencing violence or threats of violence") and can be answered with 'yes' or 'no.' It also addresses the frequency of peer victimization (daily, weekly, monthly; general occurrence). The interrater reliability is indicated as high ( $>.80)$ by the test authors. TGAM items 16-18 measured self-esteem. Of items 19-34 (complaints from the internalizing spectrum such as anxiety, depression, somatization and disorders of the attentional load), 15 items were taken from PISA (2009) (vegetative symptoms, stress-related cognitive problems, emotional instability, anxiety, somatization, depression, sleep disturbances). Cronbach's alpha (internal consistency) for the 15 PISA items is .94 [28]. Items 35-43 on perceived parental support were taken from the Berlin Social Support Scale (BSSS). The original BSSS includes six independent subscales (perceived available support, need for support, support-seeking, actual received support, provided support and protective buffering) and measures both cognitive and behavioral aspects of social support. We used one subscale (perceived available support, consisting of 8 items). Each two items capture communication, relationship, engagement, as well as parental monitoring. All 8 items were rated according to whether social support is provided either by parents, siblings, relatives, classmates, friends, teachers or others, or whether a pupil has no perceived social support at all. All four dimensions of parental behavior, were coded as $++=$ good and $-=$ bad. Respondents had to rate their agreement with the statements on a four-point scale (strongly disagree (1), somewhat disagree (2), somewhat agree (3) and strongly agree (4)). An average mean within the range of 1-4 was calculated for the subscale. A higher score indicated a greater burden. Cronbach's $\alpha$ for the four subscales of the BSSS ranges from .70 to .86 [29]. TGAM items 44-58 assess different socio-demographic variables. We assessed family characteristics by single items (parental age, living with both parents, family break-up, family break-up without contact to the separated parent, level of occupation of both parents, number and age of siblings, number of rooms of the flat, death of a parent and serious physical or mental illness 
of a parent). Gender was measured as male and female; age was written down. Grade was recorded directly. Children were classified as uninvolved, victim, bully or bully/victim. Victimization and bullying were defined as scoring higher than one point on the victim-scale and bullying-scale respectively (eight-point scale from 0 to $7 ;[0$ to 1$]=$ uninvolved, [2 to 7] = bullying). The objective was to estimate the population percentages of bullies, victims and bully/victims with the precision of a $95 \%$ confidence interval for each group.

\subsection{Data Analysis}

We used R version 3.1.1 (2014-07-10) database for our data analysis, with adjustments for stratification clustering and weighting. Descriptive statistics were obtained for the classification of the three subgroups (bully, victim and bully/victim), parenting behavior and parental characteristics (Fig. 1). Our hypothesis about the relationship between bullying and victimization, as well as about internalizing symptoms mediated by parental behavior is modeled by linear regression. The research questions were examined through a series of regression analyses. We conducted six sets of regression models to predict internalizing symptoms. Three variables were transformed prior to analysis in order to simplify the interpretation: Internalizing symptoms were transformed to a 0 -to-100-scale; bullying and victimization were transformed to a nominal scale; parental behavior was transformed to an interval scale range of -2 to +2 . In our article the non-standardized regression coefficients are reported. The models were tested with regard to their sufficient compliance with the requirements for the application of linear regression (residuals analysis). In a further step, the reproducibility of the model of effects was tested against the subscale 'victim.' The evaluation by means of path analysis included the standardized coefficients.

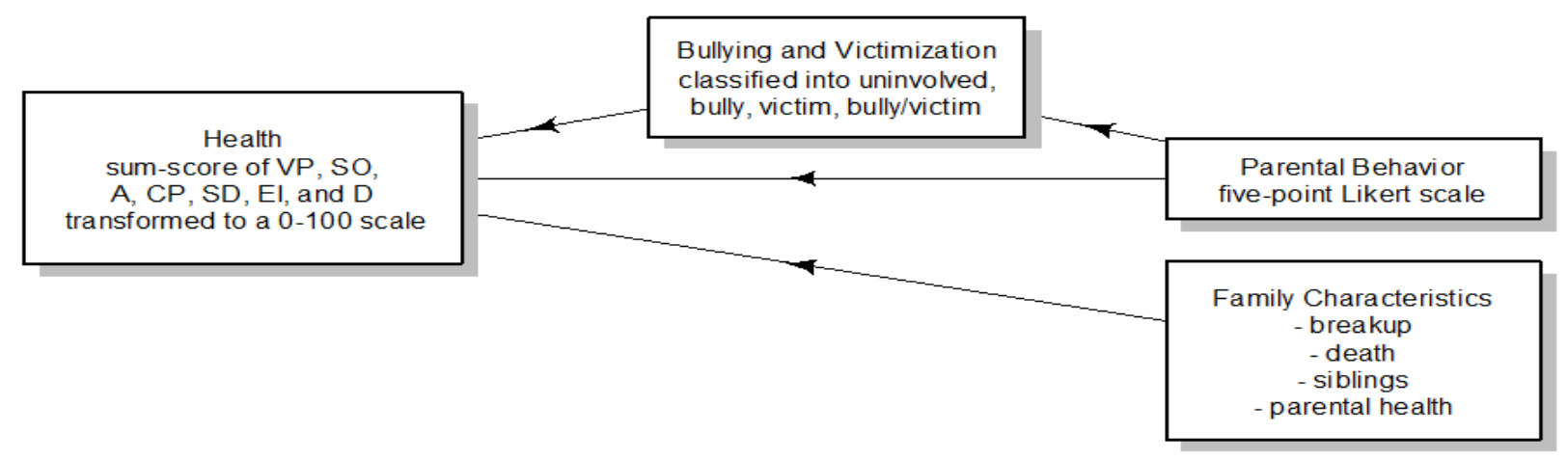

Fig. (1). Hypotheses.

\section{RESULT}

Basic descriptive statistics are shown in Table 1. Table 2 displays the coefficient and its standard errors. As shown in Table 3 we conducted six sets of regression models. (1) Base relating gender to internalizing symptoms. (2) Main Effect relating internalizing symptoms to gender, and bullying and victimization classification. (3) Mediator relating internalizing symptoms to gender, and parental behavior. (4) Main Effect + Mediator relating internalizing symptoms to gender, bullying and victimization classification, and parental behavior. (5) Interaction relating internalizing symptoms to gender, bullying and victimization classification, and parental behavior. (6) Covariates relating gender, bullying and victimization classification, parental behavior, family characteristics, and physical or mental illness of a parent to internalizing symptoms. Our final regression model was the (6) Covariates. We observed a statistical significant negative association between gender [Male] $(b=-6.06, \mathrm{t}(2628)=-6.35, \mathrm{p}<.001)$ and internalizing symptoms. We observed a statistical significant positive association between classification [victim] $(b=29.52, t(2628)=22.19, p<$ $.001)$ and internalizing symptoms. We observed a statistical significant positive association between classification [bully/victim] $(\mathrm{b}=32.12, \mathrm{t}(2628)=12.62, \mathrm{p}<.001)$ and internalizing symptoms. We observed a statistical significant positive association between classification [bully] $(b=16.57, t(2628)=7.48, p<.001)$ and internalizing symptoms. We observed a statistical significant negative association between parental behavior $(b=-2.50, t(2628)=-6.65, p<.001)$ and internalizing symptoms. We observed a statistical significant positive association between family [Brk] $(b=4.53$, $\mathrm{t}(2628)=3.21, \mathrm{p}=.001)$ and internalizing symptoms. We observed a statistical significant positive association between family [Brk.wtht] $(\mathrm{b}=4.74, \mathrm{t}(2628)=2.06, \mathrm{p}=.039)$ and internalizing symptoms. We observed a statistical significant positive association between parental health $[\mathrm{Bad}](\mathrm{b}=11.07, \mathrm{t}(2628)=5.30, \mathrm{p}<.001)$ and internalizing symptoms. 
The results of the regression indicated the eight predictors explained $25 \%$ of the variance $(\operatorname{adj} . \mathrm{R} 2=0.25, \mathrm{~F}(8,2628)=$ $108.60, \mathrm{p}<.001)$.

Table 1. Classification of sample characteristics in the full sample $(\mathrm{N}=\mathbf{2 6 3 7})$.

\begin{tabular}{|c|c|c|c|c|c|}
\hline Item & Variables & Uninvolved & Victim & Bully/Victim & Bully \\
\hline Total & & $100 \%(2002)$ & $100 \%(412)$ & $100 \%(96)$ & $100 \%(127)$ \\
\hline \multirow[t]{2}{*}{ Gender } & Female & $51 \%(1024)$ & $49 \%(203)$ & $28 \%(27)$ & $30 \%(38)$ \\
\hline & Male & $49 \%(974)$ & $51 \%(209)$ & $72 \%(69)$ & $70 \%(89)$ \\
\hline Age & & $13(12 ; 14)$ & $13(11 ; 14)$ & $13(12 ; 14)$ & $13(12 ; 14)$ \\
\hline Parental age mother & & $29(25 ; 32)$ & $28(25 ; 32)$ & $28(25 ; 32)$ & $28(25 ; 31)$ \\
\hline Parental age father & & $31(28 ; 35)$ & $31(27 ; 34)$ & $31(28 ; 35)$ & $31(28 ; 34)$ \\
\hline Parental behavior & & $0(-1 ; 1)$ & $-1(-2 ; 0)$ & $-1(-2 ; 0)$ & $0(-2 ; 1)$ \\
\hline Internalizing symptoms & & $14(0 ; 29)$ & $57(29 ; 71)$ & $57(29 ; 71)$ & $29(14 ; 57)$ \\
\hline \multirow[t]{3}{*}{ Communication } & ++ & $56 \%(1128)$ & $35 \%(146)$ & $29 \%(28)$ & $49 \%(62)$ \\
\hline & + & $9 \%(175)$ & $9 \%(39)$ & $7 \%(7)$ & $7 \%(9)$ \\
\hline & - & $35 \%(697)$ & $55 \%(227)$ & $63 \%(60)$ & $44 \%(56)$ \\
\hline \multirow[t]{3}{*}{ Parental involvement } & ++ & $48 \%(948)$ & $25 \%(104)$ & $22 \%(21)$ & $43 \%(54)$ \\
\hline & + & $19 \%(381)$ & $23 \%(92)$ & $18 \%(17)$ & $14 \%(18)$ \\
\hline & - & $33 \%(665)$ & $52 \%(212)$ & $60 \%(58)$ & $43 \%(54)$ \\
\hline \multirow[t]{3}{*}{ Parental support and onitoring } & ++ & $72 \%(1443)$ & $62 \%(255)$ & $39 \%(37)$ & $61 \%(77)$ \\
\hline & + & $20 \%(405)$ & $25 \%(101)$ & $38 \%(36)$ & $24 \%(31)$ \\
\hline & - & $8 \%(154)$ & $14 \%(56)$ & $24 \%(23)$ & $15 \%(19)$ \\
\hline \multirow{3}{*}{ Affective relationship } & ++ & $55 \%(1091)$ & $34 \%(142)$ & $27 \%(26)$ & $46 \%(58)$ \\
\hline & + & $13 \%(251)$ & $13 \%(54)$ & $19 \%(18)$ & $13 \%(17)$ \\
\hline & - & $33 \%(658)$ & $52 \%(216)$ & $54 \%(52)$ & $41 \%(52)$ \\
\hline Self-esteem & & $3(2 ; 3)$ & $3(2 ; 3)$ & $3(2 ; 4)$ & $2(2 ; 3)$ \\
\hline \multirow[t]{3}{*}{ Family characteristics } & Living with both parents & $84 \%(1682)$ & $78 \%(322)$ & $76 \%(73)$ & $79 \%(100)$ \\
\hline & Family break-up & $13 \%(252)$ & $13 \%(54)$ & $12 \%(12)$ & $17 \%(22)$ \\
\hline & $\begin{array}{c}\text { Family break-up without contact to one } \\
\text { parent }\end{array}$ & $3 \%(68)$ & $9 \%(36)$ & $11 \%(11)$ & $4 \%(5)$ \\
\hline \multirow[t]{2}{*}{ Physical or mental illness of a parent } & Good & 96\% (1916) & $89 \%(367)$ & $92 \%(88)$ & $95 \%(121)$ \\
\hline & $\mathrm{Bad}$ & $4 \%(86)$ & $11 \%(45)$ & $8 \%(8)$ & $5 \%(6)$ \\
\hline \multirow[t]{3}{*}{ Death of a parent } & No & 97\% (1946) & $97 \%(401)$ & $93 \%(89)$ & $98 \%(124)$ \\
\hline & Yes & $2 \%(50)$ & $2 \%(10)$ & $5 \%(5)$ & $2 \%(3)$ \\
\hline & NA & $0 \%(6)$ & $0 \%(1)$ & $2 \%(2)$ & $0 \%(0)$ \\
\hline \multirow[t]{6}{*}{ Number of rooms of the flat } & $>4$ & $29 \%(585)$ & $32 \%(132)$ & $32 \%(31)$ & $28 \%(35)$ \\
\hline & 4 & $19 \%(373)$ & $20 \%(81)$ & $19 \%(18)$ & $19 \%(24)$ \\
\hline & 5 & $18 \%(355)$ & $15 \%(63)$ & $17 \%(16)$ & $17 \%(21)$ \\
\hline & 6 & $11 \%(215)$ & $11 \%(45)$ & $15 \%(14)$ & $10 \%(13)$ \\
\hline & $<6$ & $21 \%(430)$ & $21 \%(87)$ & $15 \%(14)$ & $22 \%(28)$ \\
\hline & NA & $2 \%(44)$ & $1 \%(4)$ & $3 \%(3)$ & $5 \%(6)$ \\
\hline \multirow[t]{5}{*}{ Siblings } & none & $8 \%(164)$ & $11 \%(45)$ & $5 \%(5)$ & $5 \%(6)$ \\
\hline & one & $47 \%(943)$ & $45 \%(186)$ & $49 \%(47)$ & $50 \%(63)$ \\
\hline & two & $29 \%(571)$ & $25 \%(104)$ & $27 \%(26)$ & $30 \%(38)$ \\
\hline & more & $14 \%(282)$ & $16 \%(65)$ & $15 \%(14)$ & $15 \%(19)$ \\
\hline & NA & $2 \%(42)$ & $3 \%(12)$ & $4 \%(4)$ & $1 \%(1)$ \\
\hline \multirow[t]{4}{*}{ Occupation mother } & Blue-collar & $82 \%(1447)$ & $82 \%(290)$ & $83 \%(62)$ & $88 \%(98)$ \\
\hline & none & $1 \%(23)$ & $2 \%(8)$ & $4 \%(3)$ & $0 \%(0)$ \\
\hline & White-collar & $16 \%(279)$ & $16 \%(56)$ & $13 \%(10)$ & $12 \%(13)$ \\
\hline & Retired & $0 \%(7)$ & $0 \%(1)$ & $0 \%(0)$ & $1 \%(1)$ \\
\hline \multirow[t]{4}{*}{ Occupation father } & Blue-collar & $76 \%(1243)$ & $79 \%(260)$ & $79 \%(58)$ & $71 \%(72)$ \\
\hline & none & $2 \%(33)$ & $1 \%(4)$ & $3 \%(2)$ & $2 \%(2)$ \\
\hline & White-collar & $21 \%(335)$ & $19 \%(62)$ & $15 \%(11)$ & $25 \%(26)$ \\
\hline & Retired & $1 \%(16)$ & $2 \%(5)$ & $3 \%(2)$ & $2 \%(2)$ \\
\hline
\end{tabular}

Parental age: age at birth; parental behavior: sum index [-2 to +2]; statistic: percent (number of subjects), median (upper quantile, lower quantile) 
Table 2. Descriptive statistic health by classification and parental behavior.

\begin{tabular}{|c|c|c|c|c|c|}
\hline Variable & Parental Behavior & Uninvolved & Victim & Bully/Victim & Bully \\
\hline Vegetative problems & negative & $39 \%(463)$ & $73 \%(233)$ & $79 \%(63)$ & $63 \%(52)$ \\
\hline & positive & $28 \%(227)$ & $66 \%(60)$ & $75 \%(12)$ & $38 \%(17)$ \\
\hline Somatization & negative & $24 \%(285)$ & $52 \%(167)$ & $45 \%(36)$ & $38 \%(31)$ \\
\hline & positive & $21 \%(171)$ & $57 \%(52)$ & $12 \%(2)$ & $18 \%(8)$ \\
\hline Anxiety & negative & $18 \%(213)$ & $53 \%(170)$ & $52 \%(42)$ & $28 \%(23)$ \\
\hline & positive & $10 \%(86)$ & $43 \%(39)$ & $62 \%(10)$ & $9 \%(4)$ \\
\hline Cognitive problems & negative & $31 \%(372)$ & $66 \%(211)$ & $74 \%(59)$ & $60 \%(49)$ \\
\hline & positive & $26 \%(210)$ & $53 \%(48)$ & $69 \%(11)$ & $44 \%(20)$ \\
\hline Sleep disturbances & negative & $9 \%(101)$ & $22 \%(70)$ & $30 \%(24)$ & $17 \%(14)$ \\
\hline & positive & $5 \%(41)$ & $22 \%(20)$ & $0 \%(0)$ & $11 \%(5)$ \\
\hline Emotional instability & negative & $21 \%(246)$ & $47 \%(152)$ & $60 \%(48)$ & $52 \%(43)$ \\
\hline & positive & $14 \%(112)$ & $48 \%(44)$ & $44 \%(7)$ & $49 \%(22)$ \\
\hline Depression & negative & $15 \%(178)$ & $56 \%(179)$ & $46 \%(37)$ & $30 \%(25)$ \\
\hline & positive & $8 \%(69)$ & $47 \%(43)$ & $31 \%(5)$ & $11 \%(5)$ \\
\hline
\end{tabular}

Parental support - behavior: coding $[-2$ to +2$]$ were $=[1,2]$ recoded into two groups with neg. $=[-2,-1.0]$ and pos.

Table 3. Regression estimated coefficients and standard errors.

\begin{tabular}{|c|c|c|c|c|c|c|}
\hline & 1 & 2 & 3 & 4 & 5 & $\overline{6}$ \\
\hline (Intercept) & $28.79(0.77)^{* * *}$ & $22.56(0.76)^{* * *}$ & $28.47(0.76)^{* * *}$ & $22.64(0.71)^{* * *}$ & $22.65(0.72)^{* * *}$ & $21.30(0.74)^{* * *}$ \\
\hline Gender [Male] & $-4.03(1.08)^{* * *}$ & $-5.68(0.96)^{* * *}$ & $-5.22(1.06)^{* * *}$ & $-6.36(0.96)^{* * *}$ & $-6.33(0.96)^{* * *}$ & $-6.06(0.95)^{* * *}$ \\
\hline [Victim] & & $31.91(1.33)^{* * *}$ & & $30.43(1.33)^{* * *}$ & $30.21(1.46)^{* * *}$ & $29.52(1.33) * * *$ \\
\hline [Bully/Victim] & & $34.49(2.57)^{* * *}$ & & $32.89(2.56)^{* * *}$ & $32.38(2.94) * * *$ & $32.12(2.55) * * *$ \\
\hline [Bully] & & $17.19(2.25)^{* * *}$ & & $16.89(2.23)^{* * *}$ & $16.25(2.27)^{* * *}$ & $16.57(2.22)^{* * *}$ \\
\hline Parental Behavior & & & $-4.32(0.42) * * *$ & $-2.69(0.38) * * *$ & $-2.44(0.43)^{* * *}$ & $-2.50(0.38)^{* * *}$ \\
\hline [Victim] Parental Behavior & & & & & $-0.55(1.07)$ & \\
\hline [Bully/Victim] Parental Behavior & & & & & $-0.90(1.99)$ & \\
\hline [Bully] Parental Behavior & & & & & $-2.61(1.71)$ & \\
\hline Family [Brk] & & & & & & $4.53(1.41)^{* *}$ \\
\hline Family [brk.wtht] & & & & & & $4.74(2.30)^{*}$ \\
\hline Parental health [Bad] & & & & & & $11.07(2.09)^{* * *}$ \\
\hline $\mathbf{R}^{2}$ & 0.01 & 0.22 & 0.04 & 0.24 & 0.24 & 0.25 \\
\hline Adj. $\mathbf{R}^{2}$ & 0 & 0.22 & 0.04 & 0.23 & 0.23 & 0.25 \\
\hline Num. Obs. & 2637 & 2637 & 2637 & 2637 & 2637 & 2637 \\
\hline
\end{tabular}

Tab 2: Regression analysis: Regression Estimated Coefficients and Standard Errors. Internalizing symptoms sum-score transformed to a 0-100 scale.

As shown in Figs. ( 2 and $\mathbf{3}$ ) there is a positive association between the classification into bullying and victimization on the one hand and internalizing symptoms on the other hand. Victims have an approximately $30 \%$ higher score on the internalizing scale and $60 \%$ higher scores than uninvolved (on the 100-point health scale, the average for uninvolved pupils is 20 , the average for victims is 50 , for victims/bully it is 52 , and for bullies it is 34 ). Parental behavior correlates negatively with internalizing symptoms: The effects from good to bad parental behavior amount to approximately $13 \%$ on the internalizing symptoms scale. The physical and/or mental illness of a parent has a moderate effect and increases internalizing symptoms by approximately $11 \%$. The gender effect is small: Girls have an approximately $4 \%$ higher score on the internalizing scale. Family characteristics had a small effect, amounting to approximately $5 \%$ in the case of family break-ups.

The path analysis with the subscale 'victim' as a mediator confirms the results of the effects of the previous regression analysis (the significant main effects and the non-significant interaction). This shows a standardized direct effect of bullying of (beta $=.49, \mathrm{p}<0.001$ ) and a total effect of parental behavior of (beta $=.20, \mathrm{p}<0.001$ ). These results suggest that parental behavior mediates victimization to predict internalizing symptoms. 
(4) Main Effect

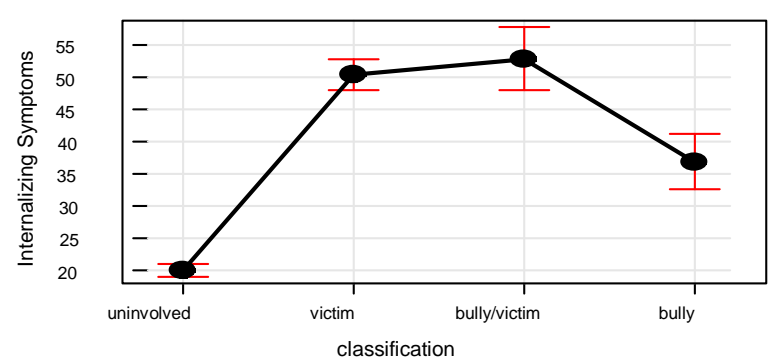

(5) Interaction Effect

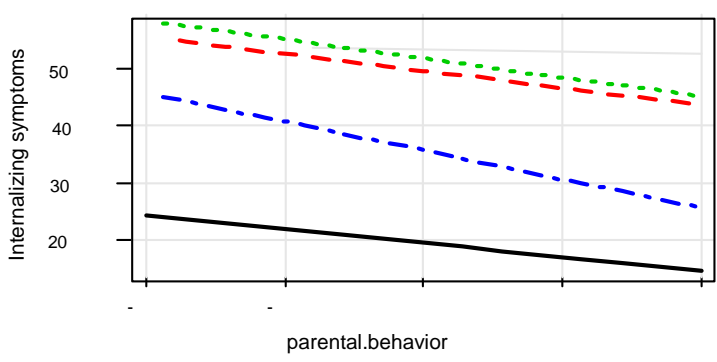

(4) Mediator Effect

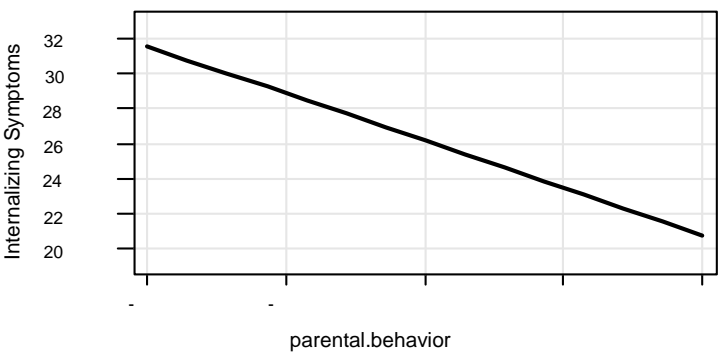

classification

uninvolved -

bully/victim . ....

bully $\quad--$

Fig. (2). Main effect vs. effect of the model.

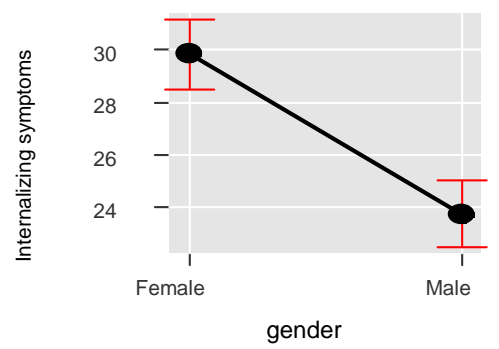

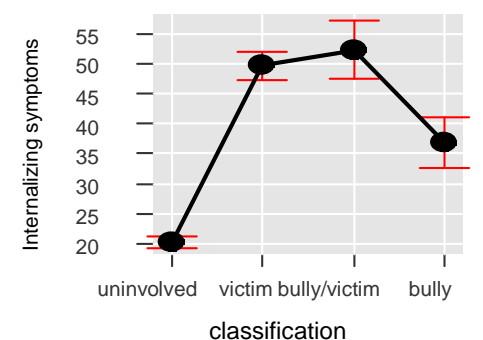

classification

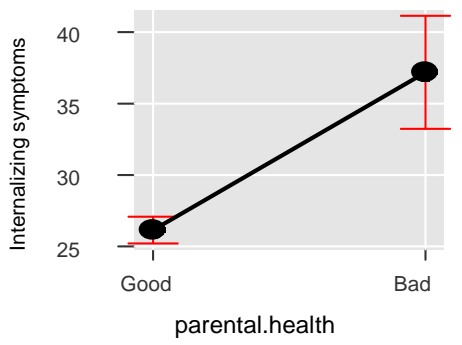

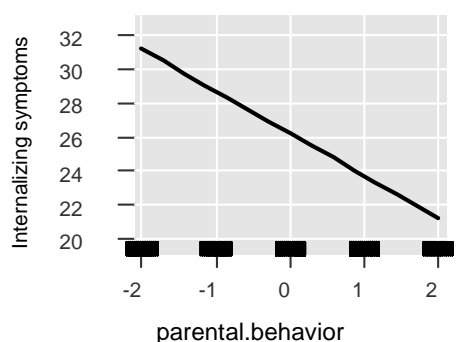

parental.behavior

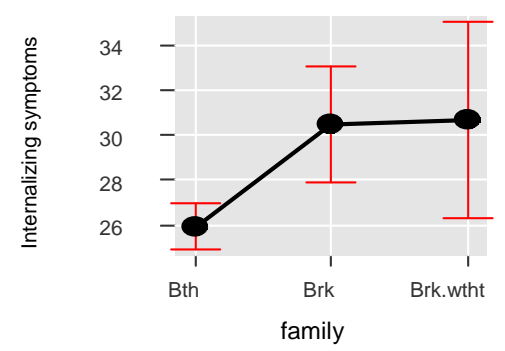

Fig. (3). Regression model.

Effect display for the regressions model (6). The red broken lines give point-wise 95-percent confidence envelopes around the fitted effects. Internalizing symptoms sum-score transformed to a 0-100 scale. bullying and victimization scales transformed to one nominal scale. Parental health: Physical/mental illness of a parent.

\section{CONCLUSION}

Prevalence of Bullying, Victimization and Bully/Victimization: Depending on the diagnostic criteria used, bullying and victimization affect about 10 to $32 \%$ of all children [6]. $75 \%$ of the respondents in our study were not involved in bullying. $4 \%$ of our respondents were rated as bullies, $16 \%$ as victims and $5 \%$ as bully/victims. In our data $21 \%$ of the pupils (at an average age of 12.6, +/ 1.3) reported being bullied [5]. data showed a total score of 19\% of pupils being 
bullied (age 13). 21\% of boys and 7\% of girls rated themselves as bullies [29]. confirmed these percentages. They researched the number of bullies and victims in a cross-national sample in 11 European countries. Five countries (Austria, the Netherlands, Spain, Switzerland and the UK) showed increased rates of reported peer-victimization (ages 8 to 18). In general, these differences result from different cut-off values, different methods of data collection, operationalization processes (subsequent operationalization or operationalization in the course of school time), sample characteristics such as pupils' age and de facto national differences.

Gender: In self-reports boys exhibit more physical and direct forms of aggression; girls report more indirect and relational forms of bullying [30]. [7] demonstrated that male bullies try to seek acceptance in the peer group by showing antisocial behavior. Female bullies seek acceptance especially of boys with high peer-related social prestige. Our descriptive data show differences in the gender distribution: Male pupils display an increase of approximately 40 percentage points in the proportion of the bully and bully/victim groups. Our sample included $51 \%$ male and $49 \%$ female participants and showed a strong, statistically significant negative association between gender (male) and the severity of internalizing symptoms (girls show an approximately 4\% higher symptomatic score).

Grade: Bullying and peer victimization peak between the ages of 12 and 14 [7]. The pupils in our study had an average age of $12.6(+/-1.3)$.

Coping Strategies Used Against Observed Bullying of others (Self-esteem): Self-esteem is considered as a mediator between peer victimization and mental health, especially with regard to the occurrence of internalizing symptoms (disorders). Research on resilience factors shows that adolescent victims of bullying who reported only a low depression were predominantly male, had higher scores of self-esteem, were feeling less socially rejected, reported lower rates of conflict with their parents and were not bullied by siblings [31]. [32] showed that low self-esteem, loneliness, hopelessness and low self-efficacy are potent moderators in the relationships between internalizing behaviors and bullying perpetration, victimization and suicide. Our data did not confirm this empirical evidence. Plausibly, the relationship depends both on the facet of self-esteem addressed in the study and on the influence of other variables (e.g., adaptive coping resources).

Social Support through Parents: For all Analyses "Perceived Parental Support" showed significant positive effects, which means that lower scores of parental behavior is associated with a higher risk of being a bully. In a meta-analysis [2] have been able to establish three key factors (predictors) which increase the risk of children becoming victims of bullying or becoming bullies themselves. These are sexual abuse, neglect and maladaptive parenting. Conversely, parenting behavior is an important protective factor in processing adversity factors, for example in the process of peer victimization (bullying). On the other hand, children from families with incongruous and inconsistent paternal interactive parental behavior, low social support and low child attachment security, which we can find predominantly in families with low Socioeconomic Status (SES), show more mental health disorders and psychosocial problems [33]. [34] demonstrated for a sample of maltreated children the positive influence of perceived social support (family, friends and others) on the development of long-term trauma symptoms [35]. revealed that social support has a mitigating effect in regard to the effects of stressful adverse life events like peer victimization. Our data confirmed the strong buffering impact of perceived parental behavior on the development of internalizing symptoms. The effects of parental behavior amount to approximately $13 \%$ on the health scale.

Parental Health Status: Maternal (OR 1.4; 95\% CI 1.1-1.8) and paternal (OR 1.5; 95\% CI 1.1-2.2) mental disorders are associated with bullying [36]. Our data analysis showed that the physical and/or mental illness of a parent has a moderate effect and increases internalizing symptoms by approximately $11 \%$.

Socio-Demographic Variables of the Families (family break-up, family break-up without contact to the separated parent, physical or mental illness of a parent, educational level of each parent, number and age of siblings, number of rooms of the flat, death of a parent): Pupils who have experienced a family break-up without contact to the separated parent show an approximately 13 percentage points higher risk of peer victimization. Our data demonstrated that family break-up is an important family characteristic, associated with an increased risk of developing internalizing symptoms. It is probably related to a lack of influence, particularly to that of absent fathers (parental monitoring). Children with physically or mentally ill parents show a 14 percentage points higher risk for internalizing symptoms. The other variables did not test as significant.

What can we deduce from our empirical data? What do we know about the relationship between peer victimization, and the development of severe internalized symptoms [37]? did some empirical research on the question of what comes first, peer victimization or mental health problems. Their data pointed out that victims of bullying generally showed 
significantly higher rates of psychosomatic and psychosocial problems than uninvolved children. In contrast children with depressive symptoms had a significantly higher risk of being victimized than children with anxiety symptoms [38]. showed the causal pathway of the basic epigenetic mechanism in the development of internalizing symptoms. Early-life stress of bullied children changes DNA methylation at a specific cytosine-phosphate-guanine (CpG) site and thus has a strong impact on HPA functioning. These studies provide evidence that the relationship between peer victimization and poor physical and mental health can be explained by differences in HPA functioning. Further research showed that changes in rates of salivary cortisol were associated with both SES and PFC activation [39]. In contrast [40], showed in an RCT that Brief Strategic Family Therapy (BSFT) (treatment duration of 12 weeks) can have an effective influence on bullying behavior, salivary cortisol concentration, anger and health-related quality of life in bullying boys. Increases in self-esteem can improve adults' cortisol regulation in stressful circumstances [41].

Overall, empirical research shows the following risk factors for peer victimization in youths between ages 9 and 15 : In an empirical study conducted in South Korea [42], demonstrated that bullies had smaller height, greater weight, lower SES, a lower paternal educational level but a higher maternal one, as well as predominantly urban residence [43]. demonstrated that early preschool behavioral, emotional and motoric problems and family break-ups are associated with an involvement in bullying and victimization [44]. summarized the data of a Turkish study on risk factors for being a bully: low educational status, mixed-age peer group, low quality of peer-relationship, poor communication with parents and not being isolated by peers. The most prevalent risk factors for being a victim were: school avoidance, low peer related social resources, less monitoring by the father, close bonding with the mother and a poor status in the peer group. The most important risk factors for being a bully/victim were: being male, a low perceived parental behavior and less monitoring by the father. We can see that there is an overlap between these three groups. Our data confirmed two of these main mediating factors and added two further factors, namely family break and parental health.

In summary it can be said: Victims have an approximately $30 \%$ higher score on the internalizing scale than bullies, and $60 \%$ higher scores than uninvolved. The results of our regression model indicated that these eight predictors (uninvolved pupils, bullies, victims, and bully/victims, gender, perceived parental behavior, family break-up with and without contact to the separated parent and parental health explained $25 \%$ of the variance $(\mathrm{r}=.50)$ in the development of severe internalizing symptoms. Parental behavior, family break-up with and without contact to the separated parent and parental health are sharing a conjoint effect, which we can call "bond-based relational skills of parents". Generally speaking: the index of early-life stress (ELS) is an indirect influencing factor for the development of children (cognitive ability, IQ, social adjustment, social adjustment, severity of mental health problems etc.). Our results indicate the protective effect of bond-based relational skills of parents (parental bonding, engaging, monitoring, enriching) mediating the psychosocial development of children especially in early child development [45].

\section{IMPLICATIONS FOR SCHOOL HEALTH}

Which conclusions should be drawn from these results? An early identification of bullying at school is thus of great importance in order to prevent the development of mental health problems among school pupils. Informed parents, teachers, school social workers and physicians (GPs and school physicians) can detect symptomatic short- and longterm consequences of bullying much earlier. Rapid screening panels can help achieve an early detection. One consequence of the present study is the development of the TGAM (Tyrolean Society of General Medicine) bullying checklist for parents, teachers and school doctors based on empirical evidence. This checklist is part of a larger detection program to support existing networks, so that all partners involved in educational responsibilities toward pupils are well informed about possible predictors of bullying and peer victimization. This can help develop new fields of action in prevention. Furthermore, reported empirical evidence of the relationship between symptomatic complaints and bullying should be given to teachers, doctors and school psychologists in training. A minimum stipulation of this study is that the aforementioned detection programs be integrated into the training of teachers. Furthermore, school authorities should require teachers not only to carry out performance-related assessments but also to conduct social monitoring reports on peer victimization. This should help mitigate or limit the empirically proven, strong impact of peer victimization on adult symptom formations and suicidal ideation. Such endeavors can thus be an important contribution to mental hygiene and the health of school-children and adolescents. Interventions at school should therefore always aim at the reduction of severe forms of aggressive behavior, at the same time preventing the development of subgroups segregated from each other [46]. More active intervention and involvement from all people who hold responsibilities at schools is recommended. 


\section{LIMITATION}

The main strength of our empirical research is its large population-based random sample of preadolescent boys and girls from urban and rural schools in Austria. A major contribution of our study is the representation of the empirical distinctness of the three researched groups - victims, bullies and victim/bullies - as well as the inclusion of different variables (individual and family characteristics, and different socio-demographic parameters). On the other hand, our dataset did not include multiple informants; we only used youth self-reports. In this context [2], showed in their metaanalysis that the proven effects of parenting behavior and the risk of becoming a victim are independent of the chosen type of data collection (self-reported by the children, by the parents or by the teachers). Most studies for the detection of peer victimization have methodically relied upon youth self-reports and population-based cross-sectionals. Furthermore, the cross-sectional character of the study renders our data less robust and makes causal interpretations impossible. But only few studies collect data longitudinally over several measuring points in time and in randomized controlled trial design. Usually longitudinal studies, carried out by retrospective data collection, record an indirect measurement of change. Self-reports will display a detection-based bias in identifying oneself as a bully. Despite these drawbacks, our results can be a useful empirical contribution for parents, teachers and physicians in order to detect and prevent bullying (victimization).

\section{CONSENT FOR PUBLICATION}

The data collection and publication was carried out with the consent of the parents, students and principal of Provincial School of Tyrol.

\section{CONFLICT OF INTEREST}

The authors declare no conflict of interest, financial or otherwise.

\section{ACKNOWLEDGEMENTS}

We want to express our thanks to the Provincial School of Tyrol, the school principals and the students and parents who participated in the data collection. Thanks also to the Tyrolean Society of General Medicine for financially supporting this study.

\section{REFERENCES}

[1] Gershon A, Sudheimer K, Tirouvanziam R, Williams LM, O’Hara R. The long-term impact of early adversity on late-life psychiatric disorders. Curr Psychiatry Rep 2013; 15(4): 352. [http://dx.doi.org/10.1007/s11920-013-0352-9] [PMID: 23443532]

[2] Lereya ST, Samara M, Wolke D. Parenting behavior and the risk of becoming a victim and a bully/victim: A meta-analysis study. Child Abuse Neg1 2013; 37(12): 1091-108.

[http://dx.doi.org/10.1016/j.chiabu.2013.03.001] [PMID: 23623619]

[3] Craig W, Harel-Fisch Y, Fogel-Grinvald H, et al. A cross-national profile of bullying and victimization among adolescents in 40 countries. Int J Public Health 2009; 54(2)(Suppl. 2): 216-24.

[http://dx.doi.org/10.1007/s00038-009-5413-9] [PMID: 19623475]

[4] Wang J, Iannotti RJ, Nansel TR. School bullying among adolescents in the United States: physical, verbal, relational, and cyber. J Adolesc Health 2009; 45(4): 368-75. [http://dx.doi.org/10.1016/j.jadohealth.2009.03.021] [PMID: 19766941]

[5] Bullying.Society at a Glance 2009: OECD Social Indicators. OECD Publishing 2009.

[6] World health organization. Risk behaviours: Being bullied and bully others. In C. Currie, C. Zanaotti, A. Morgan, D. Currie, M. Looze, C. Roberts, O. Samdal, O.R.F. Smith, \& V. Barnekow (Eds.), Social determinants of health and well-being among young people. Health behavior in School-aged Children (HBSC) study: International report from the 2009/2010 survey (pp. 191-200). Copenhagen: WHO Regional Office for Europe (Health Policy for Children and Adolescents, No.6). 2012

[7] Liu J, Graves N. Childhood bullying: A review of constructs, concepts, and nursing implications. Public Health Nurs 2011; $28(6)$ : 556-68. [http://dx.doi.org/10.1111/j.1525-1446.2011.00972.x] [PMID: 22092466]

[8] Wolke D, Copeland WE, Angold A, Costello EJ. Impact of bullying in childhood on adult health, wealth, crime, and social outcomes. Psychol Sci 2013; 24(10): 1958-70.

[http://dx.doi.org/10.1177/0956797613481608] [PMID: 23959952]

[9] Gini G, Pozzoli T. Bullied children and psychosomatic problems: A meta-analysis. Pediatrics 2013; 132(4): $720-9$. [http://dx.doi.org/10.1542/peds.2013-0614] [PMID: 24043275]

[10] Sansone RA, Watts DA, Wiederman MW. Being bullied in childhood, and pain and pain perception in adulthood. Int J Soc Psychiatry 2014; 
60(5): 449-53.

[http://dx.doi.org/10.1177/0020764013495526] [PMID: 23877335]

[11] Takizawa R, Maughan B, Arseneault L. Adult health outcomes of childhood bullying victimization: Evidence from a five-decade longitudinal British birth cohort. Am J Psychiatry 2014; 171(7): 777-84. [http://dx.doi.org/10.1176/appi.ajp.2014.13101401] [PMID: 24743774]

[12] Nilsson DK, Gustafsson PE, Svedin CG. Lifetime polytraumatization in adolescence and being a victim of bullying. J Nerv Ment Dis 2012; 200(11): 954-61.

[http://dx.doi.org/10.1097/NMD.0b013e3182718aa1] [PMID: 23124179]

[13] Copeland WE, Wolke D, Angold A, Costello EJ. Adult psychiatric outcomes of bullying and being bullied by peers in childhood and adolescence. JAMA Psychiatry 2013; 70(4): 419-26.

[http://dx.doi.org/10.1001/jamapsychiatry.2013.504] [PMID: 23426798]

[14] Roeger L, Allison S, Korossy-Horwood R, Eckert KA, Goldney RD. Is a history of school bullying victimization associated with adult suicidal ideation?: A South Australian population-based observational study. J Nerv Ment Dis 2010; 198(10): 728-33. [http://dx.doi.org/10.1097/NMD.0b013e3181f4aece] [PMID: 20921863]

[15] Zwierzynska K, Wolke D, Lereya TS. Peer victimization in childhood and internalizing problems in adolescence: A prospective longitudinal study. J Abnorm Child Psychol 2013; 41(2): 309-23. [http://dx.doi.org/10.1007/s10802-012-9678-8] [PMID: 22956274]

[16] van Dam DS, van der Ven E, Velthorst E, Selten JP, Morgan C, de Haan L. Childhood bullying and the association with psychosis in nonclinical and clinical samples: A review and meta-analysis. Psychol Med 2012; 42(12): 2463-74. [http://dx.doi.org/10.1017/S0033291712000360] [PMID: 22400714]

[17] Allison S, Roeger L, Reinfeld-Kirkman N. Does school bullying affect adult health? Population survey of health-related quality of life and past victimization. Aust N Z J Psychiatry 2009; 43(12): 1163-70. [http://dx.doi.org/10.3109/00048670903270399] [PMID: 20001416]

[18] Reijntjes A, Kamphuis JH, Prinzie P, Telch MJ. Peer victimization and internalizing problems in children: A meta-analysis of longitudinal studies. Child Abuse Negl 2010; 34(4): 244-52.

[http://dx.doi.org/10.1016/j.chiabu.2009.07.009] [PMID: 20304490]

[19] Bender D, Lösel F. Bullying at school as a predictor of delinquency, violence and other anti-social behaviour in adulthood. Crim Behav Ment Health $2011 ; 21(2)$ : 99-106. [http://dx.doi.org/10.1002/cbm.799] [PMID: 21370295]

[20] Lupien SJ, Fiocco A, Wan N, et al. Stress hormones and human memory function across the lifespan. Psychoneuroendocrinology 2005; 30(3): $225-42$ [http://dx.doi.org/10.1016/j.psyneuen.2004.08.003] [PMID: 15511597]

[21] McGowan PO, Szyf M. The epigenetics of social adversity in early life: Implications for mental health outcomes. Neurobiol Dis 2010; 39(1): 66-72.

[http://dx.doi.org/10.1016/j.nbd.2009.12.026] [PMID: 20053376]

[22] Cohen S, Janicki-Deverts D, Doyle WJ, et al. Chronic stress, glucocorticoid receptor resistance, inflammation, and disease risk. Proc Natl Acad Sci USA 2012; 109(16): 5995-9. [http://dx.doi.org/10.1073/pnas.1118355109] [PMID: 22474371]

[23] Kofink D, Boks MP, Timmers HT, Kas MJ. Epigenetic dynamics in psychiatric disorders: Environmental programming of neurodevelopmental processes. Neurosci Biobehav Rev 2013; 37(5): 831-45. [http://dx.doi.org/10.1016/j.neubiorev.2013.03.020] [PMID: 23567520]

[24] Cicchetti D, Rogosch FA. Gene $\times$ Environment interaction and resilience: effects of child maltreatment and serotonin, corticotropin releasing hormone, dopamine, and oxytocin genes. Dev Psychopathol 2012; 24(2): 411-27. [http://dx.doi.org/10.1017/S0954579412000077] [PMID: 22559122]

[25] Bratlien U, Øie M, Haug E, et al. Environmental factors during adolescence associated with later development of psychotic disorders - a nested case-control study. Psychiatry Res 2014; 215(3): 579-85. [http://dx.doi.org/10.1016/j.psychres.2013.12.048] [PMID: 24495574]

[26] Kasper H, Heinzelmann-Arnold I. Schülermobbing-Tun wir was dagegen. Buxtehude AOL 2010. Student bullying- we should do something against it. Buxtehude AOL

[27] Bergmüller S. Schulstress unter Jugendlichen: Entstehungsbedingungen, vermittelnde Prozesse und Folgen; eine empirische Studie im Rahmen von PISA 2003. Hamburg Kovacs 2007. [Academic stress among adolescents: development conditions, mediating processes and consequences; an empirical study in PISA 2003. Hamburg Kovacs]

[28] Schwarzer R. 2012. Berlin Social-Support Scales (BSSS). http://userpage.fuberlin.de/ health/soc_pol.htm , 3.12.2012

[29] Analitis F, Velderman MK, Ravens-Sieberer U, et al. Being bullied: associated factors in children and adolescents 8 to 18 years old in 11 European countries. Pediatrics 2009; 123(2): 569-77. [http://dx.doi.org/10.1542/peds.2008-0323] [PMID: 19171624]

[30] Nansel TR, Overpeck M, Pilla RS, Ruan WJ, Simons-Morton B, Scheidt P. Bullying behaviors among US youth: Prevalence and association 
with psychosocial adjustment. JAMA 2001; 285(16): 2094-100.

[http://dx.doi.org/10.1001/jama.285.16.2094] [PMID: 11311098]

[31] Sapouna M, Wolke D. Resilience to bullying victimization: the role of individual, family and peer characteristics. Child Abuse Negl 2013; 37(11): 997-1006.

[http://dx.doi.org/10.1016/j.chiabu.2013.05.009] [PMID: 23809169]

[32] Hong JS, Kral MJ, Sterzing PR. Pathways from bullying perpetration, victimization, and bully victimization to suicidality among school-aged youth: A review of the potential mediators and a call for further investigation. Trauma Violence Abuse 2014; 1524838014537904. [PMID: 24903399]

[33] McLaughlin KA, Costello EJ, Leblanc W, Sampson NA, Kessler RC. Socioeconomic status and adolescent mental disorders. Am J Public Health 2012; 102(9): 1742-50.

[http://dx.doi.org/10.2105/AJPH.2011.300477] [PMID: 22873479]

[34] Evans SE, Steel AL, DiLillo D. Child maltreatment severity and adult trauma symptoms: Does perceived social support play a buffering role? Child Abuse Negl 2013; 37(11): 934-43. [http://dx.doi.org/10.1016/j.chiabu.2013.03.005] [PMID: 23623620]

[35] Rothon C, Head J, Klineberg E, Stansfeld S. Can social support protect bullied adolescents from adverse outcomes? A prospective study on the effects of bullying on the educational achievement and mental health of adolescents at secondary schools in East London. $\mathrm{J}$ Adolesc 2011 ; 34(3): $579-88$

[http://dx.doi.org/10.1016/j.adolescence.2010.02.007] [PMID: 20637501]

[36] Shetgiri R, Lin H, Flores G. Suboptimal maternal and paternal mental health are associated with child bullying perpetration. Child Psychiatry Hum Dev 2015; 46(3): 455-65. [http://dx.doi.org/10.1007/s10578-014-0485-z] [PMID: 25096508]

[37] Fekkes M, Pijpers FI, Fredriks AM, Vogels T, Verloove-Vanhorick SP. Do bullied children get ill, or do ill children get bullied? A prospective cohort study on the relationship between bullying and health-related symptoms. Pediatrics 2006; $117(5)$ : $1568-74$. [http://dx.doi.org/10.1542/peds.2005-0187] [PMID: 16651310]

[38] Ouellet-Morin I, Wong CC, Danese A, et al. Increased serotonin transporter gene (SERT) DNA methylation is associated with bullying victimization and blunted cortisol response to stress in childhood: A longitudinal study of discordant monozygotic twins. Psychol Med 2013; 43(9): 1813-23.

[http://dx.doi.org/10.1017/S0033291712002784] [PMID: 23217646]

[39] Sheridan MA, Sarsour K, Jutte D, D’Esposito M, Boyce WT. The impact of social disparity on prefrontal function in childhood. PLoS One 2012; 7(4): e35744. [http://dx.doi.org/10.1371/journal.pone.0035744] [PMID: 22563395]

[40] Nickel MK, Muehlbacher M, Kaplan P, et al. Influence of family therapy on bullying behaviour, cortisol secretion, anger, and quality of life in bullying male adolescents: A randomized, prospective, controlled study. Can J Psychiatry 2006; 51(6): 355-62. [http://dx.doi.org/10.1177/070674370605100604] [PMID: 16786816]

[41] Liu SY, Wrosch C, Miller GE, Pruessner JC. Self-esteem change and diurnal cortisol secretion in older adulthood. Psychoneuroendocrinology 2014; 41: 111-20.

[http://dx.doi.org/10.1016/j.psyneuen.2013.12.010] [PMID: 24495612]

[42] Kim YS, Boyce WT, Koh YJ, Leventhal BL. Time trends, trajectories, and demographic predictors of bullying: a prospective study in Korean adolescents. J Adolesc Health 2009; 45(4): 360-7. [http://dx.doi.org/10.1016/j.jadohealth.2009.02.005] [PMID: 19766940]

[43] Jansen DE, Veenstra R, Ormel J, Verhulst FC, Reijneveld SA. Early risk factors for being a bully, victim, or bully/victim in late elementary and early secondary education. The longitudinal TRAILS study. BMC Public Health 2011; 11: 440. [http://dx.doi.org/10.1186/1471-2458-11-440] [PMID: 21645403]

[44] Erginoz E, Alikasifoglu M, Ercan O, et al. The role of parental, school, and peer factors in adolescent bullying involvement: Results from the Turkish HBSC 2005/2006 Study. Asia Pac J Public Health 2013. [PMID: 23359869]

[45] Bornstein M, Bradley R. Socioeconomic status, parenting and child development Monographs in parenting. New York: Psychology Press, Taylor and Francis Group 2003.

[46] Hensley V. Childhood bullying: A review and implications for health care professionals. Nurs Clin North Am 2013; 48(2): 203-13. [http://dx.doi.org/10.1016/j.cnur.2013.01.014] [PMID: 23659808]

(C) 2018 Egon et al.

This is an open access article distributed under the terms of the Creative Commons Attribution 4.0 International Public License (CC-BY 4.0), a copy of which is available at: https://creativecommons.org/licenses/by/4.0/legalcode. This license permits unrestricted use, distribution, and reproduction in any medium, provided the original author and source are credited. 